\title{
Penggunaan Artificial Neural Network pada Sinyal Elektrokardiogram untuk Mendeteksi Penyakit Jantung Aritmia Supraventrikular
}

\author{
Niendy Alexandra Yosephine ${ }^{1}$, Ratnadewi ${ }^{2}$ \\ ${ }^{1,2}$ Program Studi Teknik Elektro \\ ${ }^{1,2}$ Universitas Kristen Maranatha, J1.Suria Sumantri No.65 Bandung \\ Email : 1622048@eng.maranatha.edu ${ }^{1}$,ratnadewi@maranatha.ac.id ${ }^{2}$
}

\begin{abstract}
ABSTRAK
Aritmia supraventrikular adalah salah satu jenis gangguan irama jantung yang bersumber dari nodus AV atau impuls listrik di atrium, dengan keadaan jantung yang berdetak lebih cepat dari normal. Aritmia supraventrikular masih dapat diobati dengan obat tertentu sehingga akan sangat membantu penderita bila penyakit tersebut terdeteksi lebih awal. Pemrosesan sinyal elektrokardiogram (EKG) terhadap penyakit Aritmia supraventrikular perlu dilakukan untuk mendeteksi lebih awal adanya permasalahan pada jantung khususnya penyakit aritmia supraventrikular. Artificial Neural Network (ANN) digunakan untuk mendeteksi penyakit jantung Aritmia supraventrikular dan jantung normal karena kelebihannya dalam mengklasifikasi suatu data dengan tepat, proses yang singkat dan pengelolaan mandiri. Hasil akhir dalam penelitian ini didapatkan nilai tertinggi dalam keberhasilan mengklasifikasi berasal dari struktur algoritma Multi-Layer Perceptron. Nilai akurasi hasil pengujian tertinggi berasal dari metode pelatihan menggunakan Resilient Backpropagation yaitu sebesar 87,5\%. Nilai specificity hasil pengujian tertinggi berasal dari metode pelatihan menggunakan Levenberg Marquard sebesar $83,3 \%$. Nilai sensitivity hasil pengujian tertinggi berasal dari metode pelatihan menggunakan Resilient Backpropagation yaitu sebesar 100\%.
\end{abstract}

Kata Kunci : Aritmia Supraventrikular, ANN, EKG

\begin{abstract}
Supraventricular arrhythmias are a type of heart rhythm disorder that originates from the AV node or electrical impulses in the atria, with the heart beating faster than normal. Supraventricular arrhythmias can still be treated with certain drugs so that it will be of great help to sufferers if the disease is detected early. Electrocardiogram signal processing for supraventricular arrhythmias is necessary to detect early heart problems, especially supraventricular arrhythmias. Artificial Neural Network (ANN) is used to detect supraventricular arrhythmic heart disease and normal heart because of its advantages in classifying data correctly; the process is short and selforganizing. The final results in this study obtained the highest value in classification success derived from the structure of the Multi-Layer Perceptron algorithm. The highest accuracy value of the test results comes from the training method using Resilient Backpropagation, which is equal to $87.5 \%$. The highest specificity value of the test results comes from the training method using Levenberg Marquard of $83.3 \%$. The highest sensitivity test result value comes from the training method using Resilient Backpropagation, which is equal to $100 \%$.
\end{abstract}

Kata Kunci : Supraventricular arrhythmia, ANN, EKG 


\section{PENDAHULUAN}

Berdasarkan data World Health Organization kematian sebesar $31 \%$ atau 17.9 juta orang adalah akibat penyakit jantung (World Health Organization [Online], 2020). Deteksi dini dapat memberikan informasi tentang kelainan jantung dan membantu pasien untuk mengetahui lebih awal apakah jantungnya normal atau tidak normal. EKG digunakan untuk mengukur laju, keteraturan detak jantung, ukuran jantung, posisi bilik, kerusakan pada jantung, dan adanya efek obat tertentu. Gelombang EKG dari jantung yang normal biasanya memiliki rentang waktu gelombang yang teratur. Perubahan bentuk gelombang EKG dapat terjadi akibat aritmia yang berulang atau adanya kerusakan pada otot jantung. Aritmia adalah masalah pada irama jantung ketika organ tersebut berdetak terlalu cepat, terlalu lambat, atau tidak teratur. Aritmia supraventrikular adalah salah satu jenis gangguan irama jantung yang bersumber dari nodus AV atau impuls listrik di atrium, dengan keadaan jantung yang berdetak lebih cepat dari normal. Jantung yang berdetak begitu cepat mengakibatkan otot jantung tidak dapat mengendur di sela-sela kontraksi sehingga jantung tidak bisa memenuhi kebutuhan pasokan darah yang dibutuhkan tubuh, termasuk memenuhi pasokan darah ke otak. Kondisi seperti ini akan membuat pasien merasa pusing bahkan pingsan.

Penggunaan machine learning pada bidang medis banyak digunakan diantaranya untuk mendeteksi kanker payudara untuk mempercepat proses pendeteksian. Pada penelitian ini digunakan algoritma Support Vector Machine untuk mendeteksi apakah termasuk kanker ganas atau jinak (Chazar \& Widhiaputra, 2020). Aplikasi untuk mendeteksi kanker serviks dengan motode sistem pakar forward chaining telah dilakukan pula oleh (Chazar \& Septyanto, 2018) dan diharapkan dapat membantu masyarakat.

Tidak sedikit metode yang terus dikembangkan para peneliti untuk mendeteksi penyakit aritmia termasuk menggunakan metode Artificial Neural Network (ANN), namun belum ada yang khusus penerapannya terhadap aritmia supraventrikular. Berbagai studi menyatakan kombinasi dari nilai yang diberikan pada proses pelatihan sinyal EKG dapat meningkatkan performa deteksi penyakit yang dideteksi. Lasoed dkk., menggunakan metode Artificial Neural Network (ANN) berdasarkan performa dari sumber database aritmia yang belum ditentukan penyakit aritmia secara khusus dalam 
hal ini yaitu aritmia secara general dan mencapai nilai MSE $0.03 \%$ serta akurasi hingga 99\% pada algoritma MLP (Lassoued \& Ketata, 2018).

Berdasarkan penelitian di atas, pada penelitian ini Artificial Neural Network (ANN) digunakan untuk mendeteksi penyakit jantung aritmia supraventricular dan jantung normal karena kelebihannya dalam mengklasifikasi suatu data dengan tepat, proses yang singkat dan selforganizing. Hal ini yang melatarbelakangi pengimplementasian sistem klasifikasi Aritmia supraventrikular dengan menggunakan Artificial Neural Network (ANN).

Aritmia supraventrikular merupakan gangguan jantung yang menyebabkan jantung berdetak terlalu cepat sehingga membuat otot jantung tidak dapat mengendur disela-sela kontraksi yang mengakibatkan kurangnya pasokan darah ke tubuh atau bagian organ seperti otak. Aritmia supraventrikular merupakan penyakit aritmia yang penyebabnya berasal dari atrium atau nodus AV yang menyebabkan jantung memiliki detak jantung antara 140-250 kali per menit.

Elektrokardiogram (EKG) digunakan untuk mengamati aktivitas jantung, yaitu variasi dan kelainan selama periode waktu tertentu. Sinyal ini terdiri dari beberapa pola gelombang, puncak dan lembah sinyal EKG biasanya diberi label gelombang P, Q, R, S, T, dan terkadang U. Label gelombang EKG tersebut dapat mewakili aktivasi atrium dan repolarisasi ventrikel dan memberikan informasi penting tentang aktivitas listrik jantung.

Wavelet merupakan gelombang yang digunakan sebagai fungsi untuk mendapatkan informasi dari suatu data. Cara kerjanya yaitu gelombang mother wavelet yang digabungkan dengan suatu sinyal data tertentu akan berkolerasi bila dalam sinyal data tersebut memiliki frekuensi sinyal yang sama dengan mother wavelet yang digunakan dan mother wavelet tersebut akan diulur atau digeser. Wavelet menggunakan cara berbasis compression/decompression dalam penggunaannya. Transformasi wavelet merupakan metode trasformasi berbasis wavelet yang digunakan untuk menganalisis sinyal-sinyal non-stationer dan merupakan perkembangan dari transformasi fourier. Cara kerja tranformasi wavelet yaitu dengan menghitung konvolusi sinyal data dengan sinyal mother wavelet (Kania et al., 2007).

Principal Component Analysis (PCA) adalah analisis multi-variabel yang mentransformasi variabel-variabel awal yang saling berkolerasi menjadi variabel- 
variabel baru yang tidak saling berkolerasi dengan mereduksi sejumlah variabel tersebut sehingga mempunyai dimensi yang lebih kecil namun tetap dapat menerangkan sebagian besar keragaman variabel aslinya. Banyaknya komponen utama yang terbentuk akan sama dengan banyaknya variabel asli (Jollife \& Cadima, 2016).

Artificial Neural Network (ANN) atau Jaringan Saraf Tiruan adalah sebuah pemodelan data statistik non-linier berdasarkan sistem saraf di dalam otak manusia (Almasri, 2018). ANN dapat digunakan untuk memodelkan hubungan yang kompleks antara masukan dan keluaran untuk menemukan pola-pola pada data. Struktur model ANN dapat dilihat pada Gambar 1. Secara matematis ANN seperti graf yang memiliki node. Terdapat 3 hal yang mendasari ANN yaitu pola hubungan antar tiap jaringan atau arsitektur jaringan, metode untuk menentukan bobot penghubung atau metode pelatihan, dan fungsi yang menentukan output atau fungsi aktivasi.

Arsitektur ANN terdiri dari input, lapisan tersembunyi (hidden layer), dan keluaran (output). Lapisan input merupakan penghubung dari sumber data dan bekerja hanya dengan meneruskan data ke lapisan berikutnya. Suatu jaringan dapat memiliki satu atau lebih lapisan tersembunyi (hidden layer) yang berfungsi memperbaiki keluaran jaringan sebelumnya sehingga nilai keluaran akan semakin dekat dengan target yang diinginkan.

\section{METODE PENELITIAN}

Metode penelitian pada naskah artikel menjelaskan jenis penelitian, subjek dan objek penelitian, waktu dan lokasi penelitian, instrumen penelitian, cara pengambilan sampel, pengumpulan data, dan analisis data.

Penelitian ini menggunakan MATLAB untuk mengolah data dan data diambil dari MIT-BIH arrhythmia supraventrical database (Physionet, n.d.). Klasifikasi sinyal EKG dengan menggunakan ANN ini menghasilkan 2 klasifikasi, yaitu normal dan aritmia supraventrikular.

Pada Gambar 1 diperlihatkan langkah-langkah sistem pendeteksi sinyal EKG. Sebagai masukan adalah sinyal EKG, kemudian dilakukan pre-processing yaitu sinyal difilter menggunakan notch filter, kemudian dilakukan ekstraksi filtur dengan proses DWT dan pencarian morfologi sinyal, kemudian dilanjutkan dengan fitur selesksi dengan menggunakan PCA, dan terakhir diklasifikasi dengan ANN. 


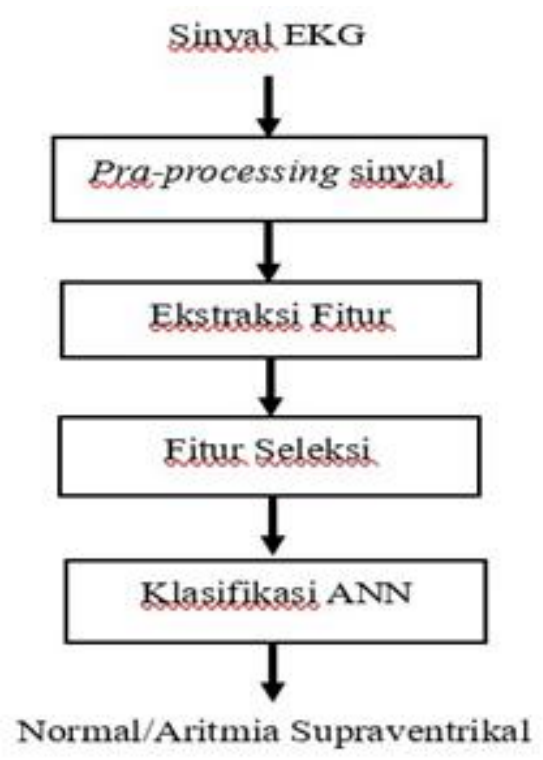

Gambar 1: Proses pendeteksian sinyal EKG

Ekstraksi fitur atau ekstraksi ciri merupakan proses untuk mengambil data-data penting yang berbeda dalam sinyal EKG sehingga tidak perlu menganalisis seluruh sinyal, dan mempersingkat waktu pengolahan. Ekstraksi fitur dibagi menjadi fitur dengan menggunakan discrete wavelet transform dan fitur morfologi EKG.

Data yang telah di ekstraksi akan digabungkan dan dibuat sebuah dataset untuk proses pengolahan seleksi fitur. Dalam hal ini fitur seleksi merupakan proses untuk mereduksi dimensi data atau transformasi ciri, fitur seleksi yang digunakan yaitu Principal Component Analysis. Proses PCA digunakan adalah proses singular value decomposition yang nantinya akan menghasilkan dimensi yang lebih sedikit dari dataset yang ada.

Struktur ANN yang digunakan untuk klasifikasi sinyal EKG adalah Feed Forward Network (FFN) khususnya Multi-Layer Perceptron (MLP) (Marius-Constantin et al., 2009), menggunakan 2 buah hidden layer yang dihubungkan dengan fungsi aktivasi Tansig (Adnan et al., 2018) dengan training function Levenberg-Marquardt (Ranganathan, 2004).

\section{HASIL DAN PEMBAHASAN}

Dengan menggunakan supervised learning model maka metode validasi yang digunakan adalah confusion matrix dengan hasil yang akan didapatkan adalah nilai 
keakuratan, nilai specificity, dan nilai sensitivity untuk menunjukkan performa sistem yang dibuat dalam menentukan penyakit aritmia supraventrikal dan normal.

Data dengan nama file 100m merupakan subjek normal dan data dengan nama file 800m merupakan subjek aritmia supraventrikular. Subjek dengan jantung normal dimulai dari 100m hingga 234m sedangkan subjek dengan jantung aritmia dimulai dari subjek ke $800 \mathrm{~m}$ hingga $840 \mathrm{~m}$.

Gambar 2 merupakan sinyal normal dan Gambar 3 merupakan sinyal aritmia sebelum melalui proses apapun dalam pengolahan.

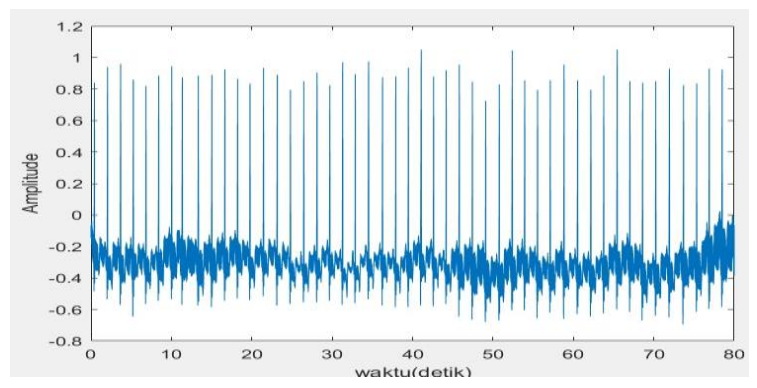

Gambar 2: Data 100m sinyal EKG normal

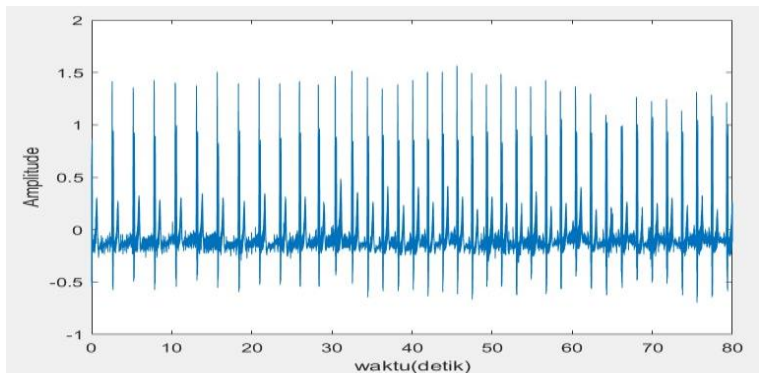

Gambar 3: Data 800m sinyal EKG aritmia supraventrikular

Gambar 4 merupakan sinyal normal dan Gambar 5 merupakan sinyal aritmia setelah dihilangkan sinyal noisenya. Gambar 6 dan 7 merupakan gambar puncak sinyal yang terdeteksi dalam jantung normal dan jantung dengan kelainan aritmia supraventrikular. 


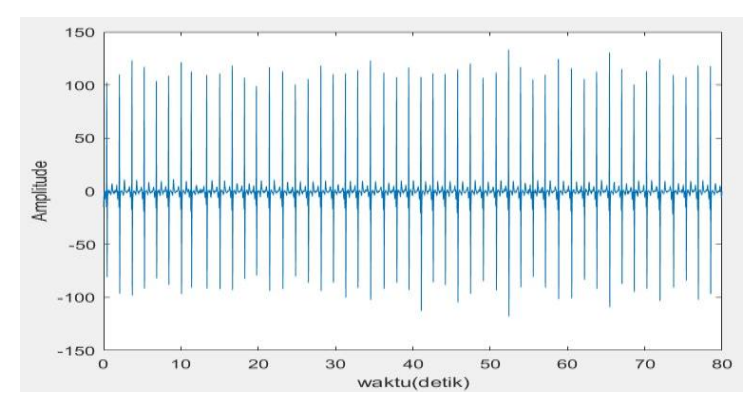

Gambar 4: Data 100m sinyal EKG normal tanpa noise

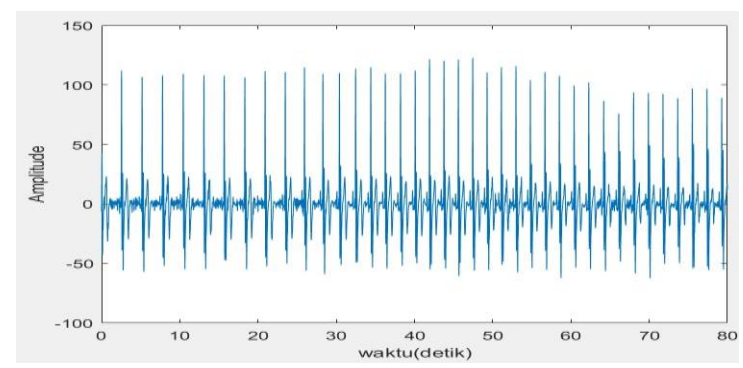

Gambar 5: Data 800m sinyal EKG Aritmia supraventrikular tanpa noise

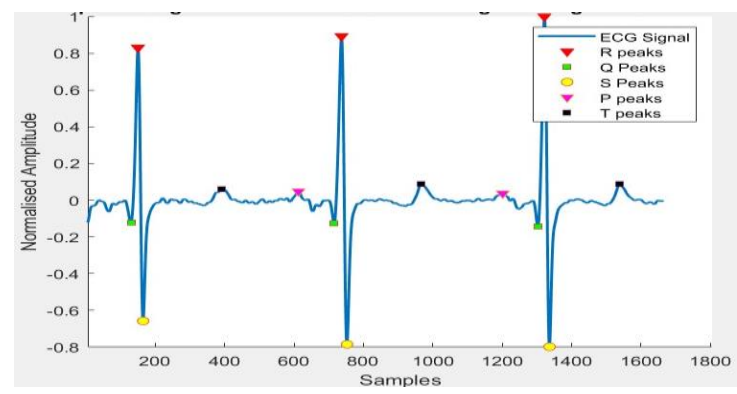

Gambar 6: Data 100m sinyal EKG normal

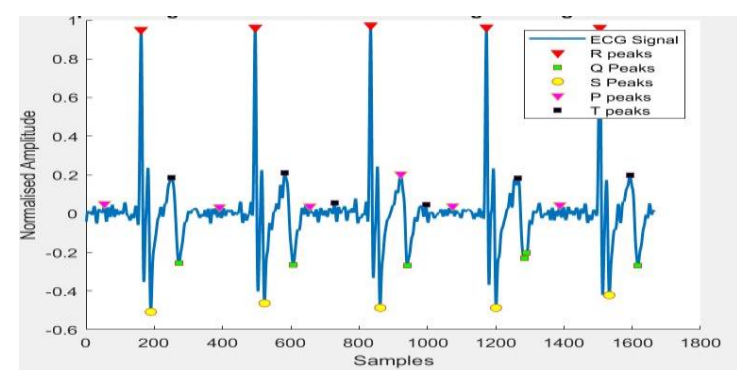

Gambar 7: Data 800m sinyal EKG aritmia supraventrikular 


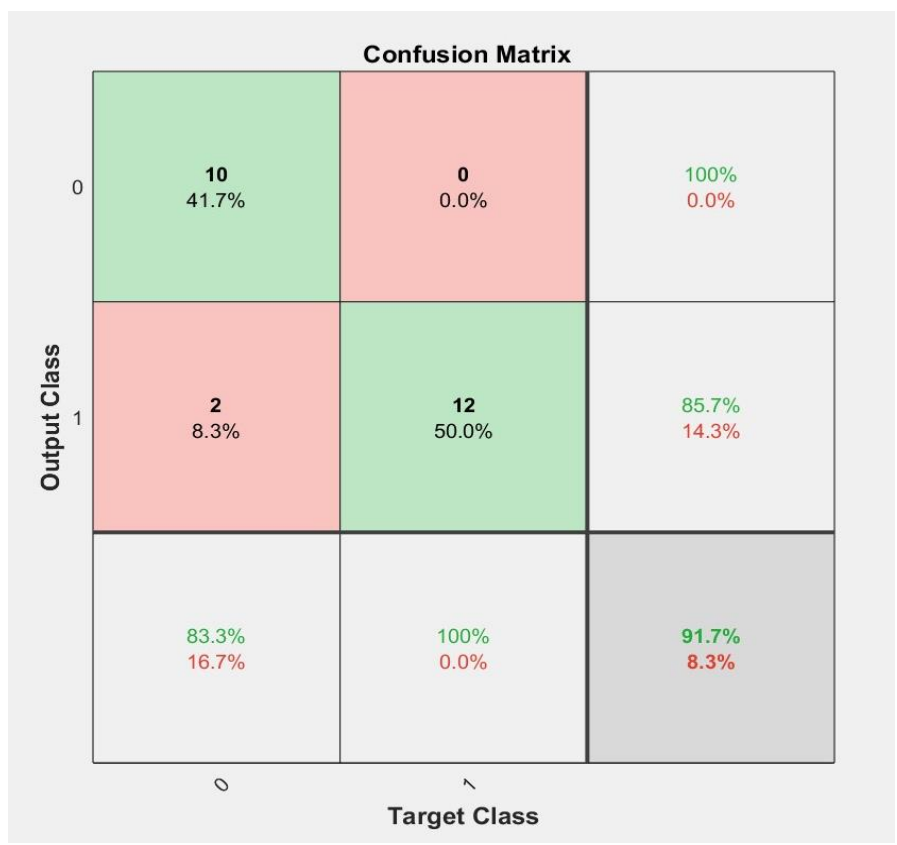

Gambar 8: Confusion matrik pelatihan-MLP-LM

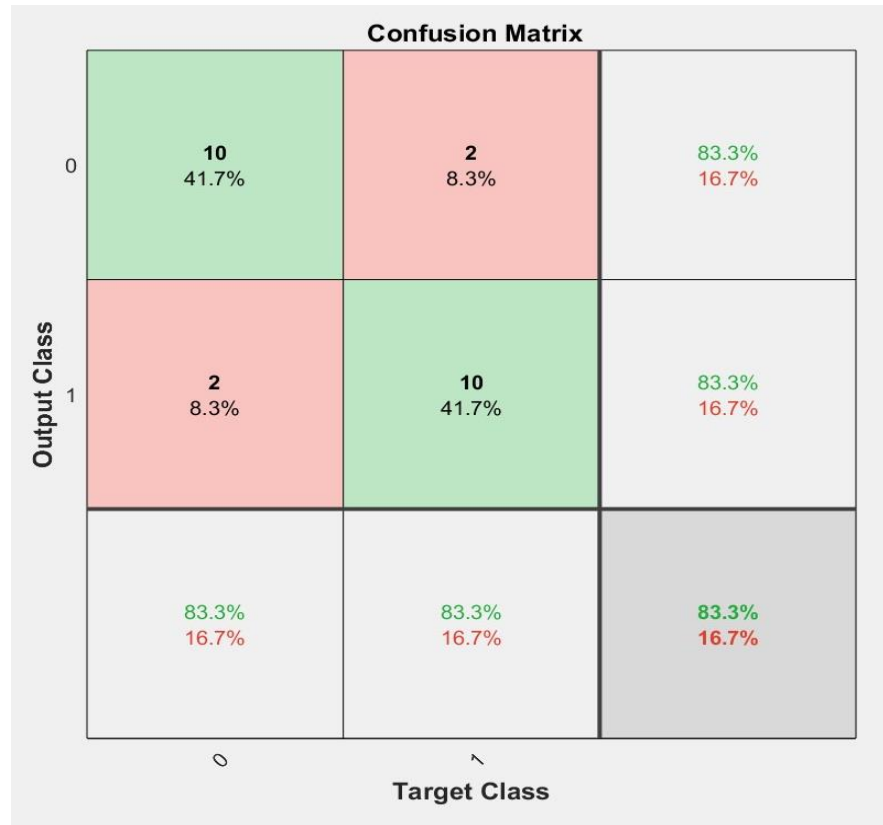

Gambar 9: Confusion matrik pengujian MLP-LM

Tabel 1. Persentase Akurasi

\begin{tabular}{lrr}
\hline & Pelatihan & Pengujian \\
\hline Akurasi & $91.7 \%$ & $83.3 \%$ \\
\hline Specitivity & $100 \%$ & $83.3 \%$ \\
\hline Sensitivity & $83.3 \%$ & $83.3 \%$ \\
\hline
\end{tabular}




\section{SIMPULAN}

Proses klasifikasi penyakit Aritmia supraventrikular menggunakan Artificial Neural Network berhasil diimplementasikan. Hasil pengujian dengan struktur ANN multi-layer perceptron menghasilkan nilai akurasi, specitivity dan sensitivity sebesar $83.3 \%$.

\section{DAFTAR PUSTAKA}

Adnan, J., Daud, N. G. N., Ishak, M. T., Rizman, Z. I., \& Rahman, M. I. A. (2018). Tansig activation function (of MLP network) for cardiac abnormality detection. AIP Conference Proceedings, 1930(February). https://doi.org/10.1063/1.5022900

Al-masri, E. (2018). An Artificial Neural Network Approach for the Detection of Abnormal Heart Rhythms. 19(2).

Chazar, C., \& Septyanto, V. (2018). SISTEM PAKAR DIAGNOSA PENYAKIT KANKER SERVIKS MENGGUNAKAN METODE FORWARD CHAINING. Informasi, $\mathrm{X}(1), \quad 44-77 . \quad$ http://informasi.stmik-im.ac.id/sistem-pendukungkeputusan-memilih-jurusan-di-perguruan-tinggi-menggunakan-metode-analyticalhierarchy-process-ahp/

Chazar, C., \& Widhiaputra, B. E. (2020). Machine Learning Diagnosis Kanker Payudara Menggunakan Algoritma Support Vector Machine. INFORMASI (Jurnal Informatika Dan Sistem Informasi), 12(1), 67-78.

Jollife, I. T., \& Cadima, J. (2016). Principal component analysis: A review and recent developments. Philosophical Transactions of the Royal Society A: Mathematical, $\begin{array}{llll}\text { Physical and } & \text { Engineering 374(2065). }\end{array}$ https://doi.org/10.1098/rsta.2015.0202

Kania, M., Fereniec, M., \& Maniewski, R. (2007). Wavelet denoising for multi-lead high resolution ECG signals. 6th International Conference on Measurement, MEASUREMENT 2007 - Proceedings, 7(4), 400-403.

Lassoued, H., \& Ketata, R. (2018). Artificial Neural Network classifier for heartbeat arrhythmia detection. Proceedings of Engineering and Technology-PET, 22(March 2017), 67-72.

Marius-Constantin, P., Balas, V. E., Perescu-Popescu, L., \& Mastorakis, N. (2009). Multilayer perceptron and neural networks. WSEAS Transactions on Circuits and Systems, 8(7), 579-588.

Physionet. (n.d.). PhysioNet. https://archive.physionet.org/cgi-bin/atm/ATM

Ranganathan, A. (2004). The Levenberg-Marquardt Algorithm 3 LM as a blend of Gradient descent and Gauss-Newton itera. Internet Httpexcelsior Cs Ucsb Educoursescs290ipdfL MA Pdf, 142(June), 1-5. http://twiki.cis.rit.edu/twiki/pub/Main/AdvancedDipTeamB/the-levenberg- 
marquardt-algorithm.pdf

World Health Organization [Online]. (2020). Jumlah kematian akibat penyakit jantung. 2020. https://www.who.int/health-topics/cardiovascular-diseases/ 